\title{
Nature to Nurture- Identifying phytochemicals from Indian medicinal plants as prophylactic medicine by rational screening to be potent against multiple drug targets of SARS-CoV-2
}

\author{
Authors: Pratap Kumar Parida, ${ }^{1 \#}$, Dipak Paul ${ }^{2 \#}$, DebamitraChakravorty ${ }^{3 * \#}$ \\ ${ }^{1}$ Pratap Kumar Parida, PhD (Research Scientist- Computational Biology \&Bioinformatics) \\ Noor Enzymes Private Limited, 37-B, Darga Road, Kolkata - 700 017, India \\ ${ }^{2}$ Dipak Paul, PhD(Scientist - Technical Services) \\ Noor Enzymes Private Limited, 37-B, Darga Road, Kolkata - 700 017, India \\ ${ }^{3 *}$ Corresponding author \\ DebamitraChakravorty, $\mathrm{PhD}$ (Project Lead - Computational Biology) \\ Novel Techsciences (OPC) Private Limited, 37-B, Darga Road, 1st Floor, Kolkata - 700 017, India \\ E-mail: dc(at)noveltechsciences.com \\ ${ }^{\#}$ All the authors have contributed equally to the paper.
}

\begin{abstract}
The COVID-19 pandemic resulted in millions of people being quarantined, impacting the world economy and health sector. There is no existing proven treatment for this disease. It may takea long time until a good candidate vaccine or a potent drug is made available in the market. Therefore, there is a need to search for alternative therapy. In the context, this work explored natural compounds from Indian medicinal plants to develop a prophylactic treatment regimen that will be instrumentalin controlling the spread of the deadly virus. In this work 1916 phytochemicals from 55 Indian medicinal plants, reported to possess antiviral properties, were subjected to virtual screening on 8 structural and non-structural SARSCoV-2 protein targets. Docking interactions, ADME and toxicity profiles of the 66 screened phytochemicals were correlated with 21 repurposed drugs that have been most cited in literature to be effective against SARS-CoV-2. Steroidal lactones from Withaniasomnifera and triterpenoids from Azadirachtaindica- with docking score ranging from $-13 \mathrm{kcal} / \mathrm{mol}$ upto $-6 \mathrm{kcal} / \mathrm{mol}$ were identified to occupy the top scoring virtually screened phytochemicals against the various targets of SARS-CoV-2. Importantly this work proposes that a concoction of these phytochemicals can act as prophylactic anti-viral medicine to control the spread of SARS-CoV-2 and also enhance natural immunity as the first line of defence towards such a deadly virus.
\end{abstract}

Key Words:SARS-CoV-2, anti viral, India, phytochemicals, prophylaxis, concoction, repurposed drugs 


\section{Highlights}

- Rational screening of phytochemicals that can bind to various targets of SARS-CoV-2 and proposing a concoction that can act as prophylaxis;

- Molecular docking to find interaction between phytochemicals from 55 Indian Medicinal plantstargeting eight SARS-COV-2 targets (structural and non structural proteins);

- Prediction of drug-likeness from the top hits of phytochemicals and their maximum recommended therapeutic dose;

- Comparison of the docking results with 21 repurposed drugs currently being considered to treat COVID-19.

\section{Introduction}

Globalization has led to increased travel and exploitation of natural environment leading to escalation in occurrence of pandemics. Despite global preparedness, challenges persistas modern medicine still lacks effective immunization and drugs due to the development of potential multi drug resistant pathogenic mutants. Among all pathogens, RNA viruses are more contagious as they havehigh ratesof evolution due to natural selection on their mutation rate (Duffy, 2018; Kayla et al., 2018). This leads to their ability to emerge in novel hosts and escape vaccine-induced immunity (Duffy, 2018; Peck et al., 2018). Examples of RNA viral outbreaks are that of dengue virus, influenza virus, measles virus, severe acute respiratory syndrome (SARS) virus, West Nile virus and recently the severe acute respiratory syndrome coronavirus 2 (SARS-CoV-2) (Lin et al., 2014, WHO, 2019). The latter has been declared to be pandemic on $11^{\text {th }}$ March 2020 by the World Health Organization [WHO 2020]. Though vaccines and antiviral agents are the most effective against treatment of viral outbreaks, development of vaccine may take upto 12 - 18 monthsand novel drug discovery is known to take several years (Lancet, 2020).Thusprophylaxisand immediate treatment is the need of the hour. In this context natural products provide an excellent resource for novel anti-viral drug development (Lin et al., 2014). Phytochemicals from plants have been reported to possess anti-viral properties against rabies virus, Human immunodeficiency virus, Chandipura virus, Japanese Encephalitis Virus, Enterovirus, Influenza A/H1N1 and other influenza viruses, SARS coronavirus (Ganjhuet al., 2015).In the review by Ganjhuet al., 2015 it was also shown that combination of extracts from different plant species resulted in their anti-viral effect. Thus if 
such formulation can be developed against SARS-CoV-2 it can act as prophylaxis and aid in "flattening the curve" by attenuating viral load of the ongoing pandemic. It was also reported that combined uses of interferons and phytoconstituents facilitated anti-viral therapy (Cinatlet al., 2003). Therefore, concoction of phytoconstituents, which can be synthesized to reduce pressure on the natural sources, can also find use in combination therapy for SARS-CoV-2. The same can also be used as an immunopotentiating agent in combination with the vaccines that are being developed against SARS-CoV-2. Furthermore, semi-synthetic molecules can be developed to overcome if any inherent limitations existin using theoriginal molecule.

In the context of exploring natural compounds from plants as anti-viral agents- it can be mentioned here that India is home to plethora of indigenous medicinal plants that have been used in traditional medicine for centuries. Since the vedic period (more than 2000 years ago) medicinal plants are used as ayurvedic medicines in Indian subcontinent (Saini, 2016). Traditional Indian plants, to name a few,Azadirachtaindica, Curcuma longa, Bacopa monnieri and Zinger officinaleare known to possess anti-viral properties (Nadkaraniet al., 1976; Pathaket al., 2013). The anti-viral properties of these plants is due to the presence of phytochemicals such as polysaccharides, triterpenes, phenolic acids, alkaloids, proanthocyanidins and anthraquinones (Ganjhuet al., 2015). For example, a phenolic compound isolated from Curcumin was reported to interfere with Herpes Simplex Virus-1 replication (Kutluayet al., 2008). Chebulagic acid and Punicalagin from Curcumin have also been reported to have activity against dengue virus by inhibiting early steps of virus entry (Lin et al., 2013). Furthermore, research and digitisation have succeeded to give access to the structures of these phytochemicals (Poluret al.,2011; Pathaniaet al., 2015; Mohanrajet al., 2018). Example of one such database is IMPPAT (Mohanrajet al., 2018). This aforementioned vast literature of success presents us with a huge scope to explore the phytochemicals from these medicinal Indian plants, through in silico virtual screening, for drug development against SARS-CoV-2 targets.

Selection of drug targets from the pathogen is the first filter for the success of in silico drug designing. As of March 25 th 2020 , 104 SARS-CoV-2 structures have been deposited in the RCSB Protein Data Bank (RCSB PDB). Thorough literature survey showed that proteins involved in viral entry (Spike glycoprotein) and replication(16non structural proteins) can be targeted for drug discovery. Thus, in this work, keeping in mind that nature always nurtures us, virtual screening of a vast library of phytoconstituentsfrom Indian medicinal plants known to have anti-viral properties, has been carried out to identify complementary or alternative therapy for SARS-CoV-2. Conclusively this work proposesa concoction of phytoconstituents 
from different plant sources from India that can act as prophylactic anti-viral medicine to control the spread of SARS-CoV-2 and also enhance natural immunity as the first line of defence towards such a deadly virus.

\section{Computational methodology}

The main aim of this work was to identify natural sources and their phytochemicals from Indian medicinal plants that can be repurposed as an alternative therapy for SARS-Cov2 or be developed as immune-potentiating agents in combination with the future vaccines or drugs. The method uses in silico screening techniques like rational virtual screening and drug-likeness calculations on an in- house developed 3D chemical structure database of phytochemicals from Indian medicinal plants. This was followed by their comparison (docking scores, drug-likeness and binding interactions) to the already reported repurposed drugs having potentialto treat COVID-19. The overview of the methodology has been illustrated in Figure 1.The database of the phytochemicals can be obtained on request from the authors.

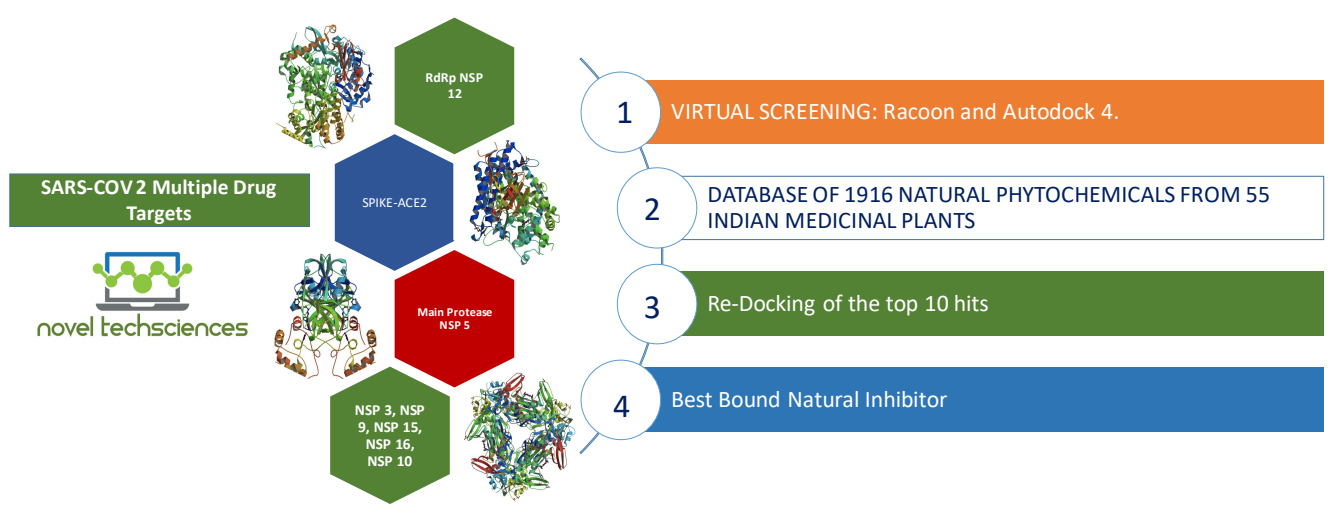

Figure 1. The overview of the methodology employed to rationally screen phytochemicals from Indian medicinal plants as potential drug like compounds against 8 structural and nonstructural targets of SARS-CoV-2. Virtual screening of 1916 phytochemicals was performed using Autodock4 and Racoon. There were 8 SARS-CoV-2 targets and 10 binding sites considered for rational screening in this work.

\section{Database creation of natural compounds from Indian medicinal plants}

55 Indian medicinal plants were identified from literature to have anti-viral properties(Table S1). Phytochemicals from the 55 sources were searched in literature and their three dimensional (3D) structures were obtained from PubChem which is an is an open chemistry database at the National Institutes of Health (NIH). The SMILES format 
(Simplified Molecular Input Line Entry System) of the phytochemicals that lacked 3D structures in PubChem were submitted to CORINA Classic to obtain their 3D structures (Sadowski et al., 1994). We could obtain the structures of 1916 phytochemicals. To compare and validate our docking results, 3D structures of 21repurposed drugs reported to have potential inhibitory effect against SARS-CoV-2 and most cited in literature in the years 20192020 were also collected from PubChem and docked against the targets of SARS Cov-2 were used in this work. The number of citations were counted by literature survey and nonredundancy of the dataset was maintained. The number of citations, FDA approval status and COVID-19 FDA approval status have been presented in Table S3.

\section{Target selection from crystal structures of SARS-CoV-2}

Out of the 105 structures of various proteins of SARS-CoV-2 deposited in RCSB PDB as of March, 2020, a total of 8 non redundantand high resolution structures were targeted for in silico virtual screening (Table 1). The main protease, RNA dependent RNA polymerase (NSP 12), NSP 3 (role in replication), NSP 9 (RNA-binding protein), NSP 10 (cofactor for the activation of the replicative enzyme), NSP 15 (endoribonuclease activity), NSP 16 (methyltransferase activity) and the spike glycosylated protein required for viral entry by binding to the ACE-2 receptor were targeted. The binding sites were identified from literature andHotSpot Wizard analysis (Pavelkaet al., 2009). Thekey residues for molecular docking grid generations are presented in Table 1. For example, the binding site chosen for docking in the spike protein (PDB ID: 6lzg) was with the residues which are in the ACE-2 receptor binding interface. These residues can be identified from its PDB structure. It can be noted here that in the case of the RNA dependent RNA polymerase (NSP 12), three sites were considered for docking analysis: (1) The RNA binding site, (2) NSP12-NSP7 interface and (3) NSP12-NSP8 interface. Sites 2 and 3 were considered for virtual screening because NSP 7 and NSP 8 are the cofactors of NSP 12 (Gao et al., 2020). Therefore, it was presumed that targeting these interfaces can disrupt the functioning of RNA dependent RNA polymerase and thus werechosen as allosteric drug binding sites.

Table 1: The targets of SARS Cov-2 and their binding site residues used for virtual screening

\begin{tabular}{lll}
\hline Protein Name & PDB ID & ${ }^{*}$ Identified Drug Binding Site Residues \\
\hline Spike Protein & 6lzg & K417, G446, Y449, Y453, N487, G496, Q498, \\
& & T500, N502 \\
Main Protease (NSP 5) & 6lu7 & T24-T26, H41, M49, F140-C145, H163-P168, \\
& & H172, D187-Q192
\end{tabular}




\begin{tabular}{|c|c|c|}
\hline NSP 10-NSP16 Interface & $\begin{array}{l}\text { 6w4h } \\
\text { (chain B) }\end{array}$ & N4293-Y4349 \\
\hline $\begin{array}{l}\text { NSP 12-RNA Binding site } \\
\text { catalytic }\end{array}$ & $6 \mathrm{~m} 71$ & $\begin{array}{l}\text { V557, D618, D623, G680, N691, S759-D761, } \\
\text { D851-I864 }\end{array}$ \\
\hline NSP 12-NSP7 Interface & $6 \mathrm{~m} 71$ & T409, K411-F415, Y420, E431, F440, F442, A443 \\
\hline NSP 12-NSP 8 Interface & $6 \mathrm{~m} 71$ & $\begin{array}{l}\text { L270-Y273, P323-K332, V338-V441, F368-F407, } \\
\text { P505-S518, M666 }\end{array}$ \\
\hline NSP 16-NSP10 Interface & $6 \mathrm{w} 4 \mathrm{~h}$ & $\begin{array}{l}\text { K6836-M6839, V6842, T6846, K6874- P6878, } \\
\text { Q6881-R6885, V6902-D6904, L7042-S7046 }\end{array}$ \\
\hline NSP 3 & 6w02 & A21-V23, A38-A50, L126 -F132, A154-L160 \\
\hline NSP 9 & $6 w 4 b$ & R100-T110 \\
\hline NSP 15 & 6w01 & E234, S244-L249, P272, S289, E340, Y343, H250 \\
\hline
\end{tabular}

${ }^{*}$ Residue numbering follows the RCSB PDB structures.

Rational screening of the phytochemical library with the 8 drug targets from SARS-CoV-2

MGLTools-1.5.6 was used for the generation of grid file and the docking file parameters. The grid box parameters for each of the proteins are given in the Table S2. Molecular docking of all the compounds was performed using the Raccoon plug-in of Autodock 4. The configurations files generated from MGLTools-1.5.6 are incorporated in the Raccoon plug-in package. The docking was run with 10 Lamarkian Genetic Algorithm (LGA) runs for virtual screening with the default parameters of Autodock 4.2. Further, for each of the 8 targets, phytochemicals with lowest binding energies $(\mathrm{kcal} / \mathrm{mol})$ were identified and subjected for re-docking for 100 LGA runs. BIOVIADiscovery StuioVisualiser (Dassault Systèmes BIOVIA, 2020). Further the residue evolutionary conservation scores of the binding pocket residues were calculated using ConSurf server (Ashkenazy et al., 2016).

\section{Drug-likeness Properties of the Phytochemicals and the Repurposed Drugs}

Drug-likeness properties based on Lipinki Rule of 5 and Adsorption, Distribution, Metabolism, Excretion (ADME) properties were calculated using SwissADME(Daina et. al 2014, Daina et. al 2016, Daina et. al 2017)Toxicity profiles (T) were calculated by the vNN web server(Schymanet al., 2017) and compared for each top 10 scoring ligands and the 21repurposed drugshaving potential to be developed into good drug candidates against SARS $\mathrm{CoV}-2$. The significant pharmacokinetic parameters for ADME/T associated properties of Gastro Intestinal absorption (GI), Blood Brain Barrier permeation (BBB), CYP inhibition, pharmacokinetic properties like Lipinski rule of 5 (Lipinski et al.,2001), PAINS (Baellet al., 2010) and Brenk (Brenket al., 2008) and Lead likeness were calculated (Teague et al., 1999). 
Further, comparative analysis of ADME/T properties between the phytochemicals and the 21 drugs were performed by cross correlation matrix calculated using Heatmapper (Babicket al., 2016). The maximum recommended therapeutic dose (MRTD) was also predicted using vNN-ADMETserver (Schymanet al.,2017). MRTD is the predicted upper daily safe dose (Contreraet al., 2004) for phase I clinical trials.

\section{Results and Discussion}

About half of all approved drugs between 1981 and 2010 were shown to be natural compound based (Stratton et al., 2015). It has been reported that more than 100 natural product derived drugs are undergoing clinical trials (Harvey et al., 2008). Natural compounds are unique, when compared with synthetic drugs in terms of more complex scaffolds and chiral centres and have huge diversity (Zhao et al., 2019).Examples of natural compounds with known safety profiles and potent anti-viral properties are isoflavones and artemisinin (Huang et al., 2020). Flavonoids were reported to have effect against RNA viruses (Kaul et al., 1985). Many researchers have reported the beneficial effect of natural compounds in treating HIV infections (Reiter et al., 2015; Salehiet al., 2018) and in the treatment of important chronic diseases like asthma (Moulton et al., 2011), Parkinson's (Dashtipouret al., 2007), cancer (Rajkumar et al., 2011). Recently, Khan et al., 2020 identified flavone and coumarine derivatives as promising leads targetting the main protease of SARS-CoV-2. Hydroxychloroquine was also observed to significantly decrease SARS-CoV-2 infection (Gautretet al., 2020). Li et al., 2020 reported that traditional Chinese herbal medicine treatments alone or in combination with western medicine can be successful in preventing and treating COVIS-19 (Li et al., 2020). Based on these reports it is clear that it is necessary to repurpose natural compounds especially phytochemicals as prophylaxis to manage patients with COVID-19. In this context, India is a rich resource of medicinal plants, many of which have antiviral properties (Jassimet al., 2003; Jadhav et al., 2012).Hence, the phytochemicals from these natural sources can be explored to identify bioactive drugs with no or minimal side-effects (Tahir et al., 2019).

Therefore, in this work 1916 phytochemicals from 55 Indian medicinal plants, reported to possess anti-viral properties, have been subjected to virtual screening on 8 SARSCoV-2 targets- selected based on two broad categories: (1) Proteins required for RNA synthesis, replication and assembly and (2) proteins required for viral entry. 


\section{Rational Screening anddrug-likeness properties of the phytochemicals and the repurposed Drugs}

Rational screening made it possible to identify 66 phytochemicals that can be potent inhibitors against the 8 drug targets of SARS-COV-2. The maximum percentage oftop scoring phytochemicals that docked to the 8targets of SARS-COV-2 were steroidal lactones from Withaniasomnifera(37\%)and triterpenoids fromAzadirachtaindica(19\%) with docking score ranging from $-13 \mathrm{kcal} / \mathrm{mol}$ upto $-6 \mathrm{kcal} / \mathrm{mol}$ (Fig. 2A, Table S1).It can be noted here that the steroidal lactones from Withaniasomniferahave been previously reported by many researchers to possess anti-viral effect against Herpes Simplex virus replication (Grover et al., 2012), H1N1 influenza virus (Cai et al., 2015) and Chikungunya Virus (Jain et al., 2018).Similarly, triterpenoidsfromAzadirachtaindicahave been reported to have anti-viral effect against Herpes Simplex virus (Bharitkaret al., 2013), influenza virus (Ahmad et al., 2016) and coxsackievirus virus B-4 (Badamet al., 1999). Therefore, it can be mentioned here that based on these reports and our work, there arises a scope tofurther experimentally explorethese phytochemicals in order toanalyse their efficacy against treating COVID 19 patients.

A

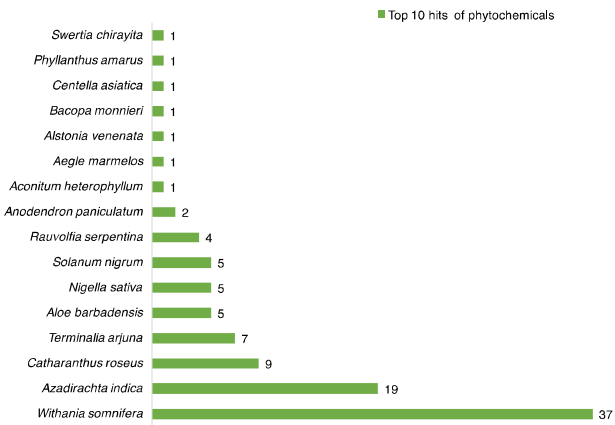

c

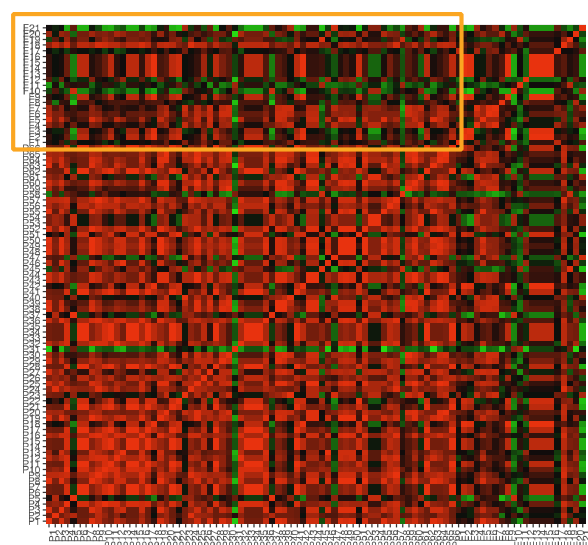

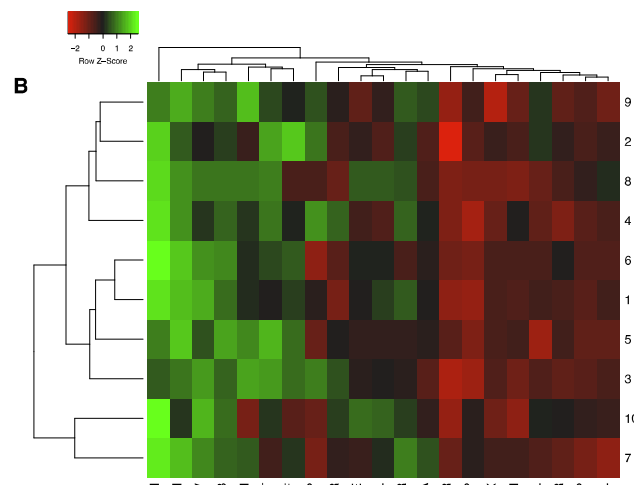

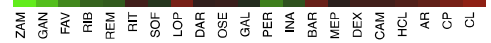

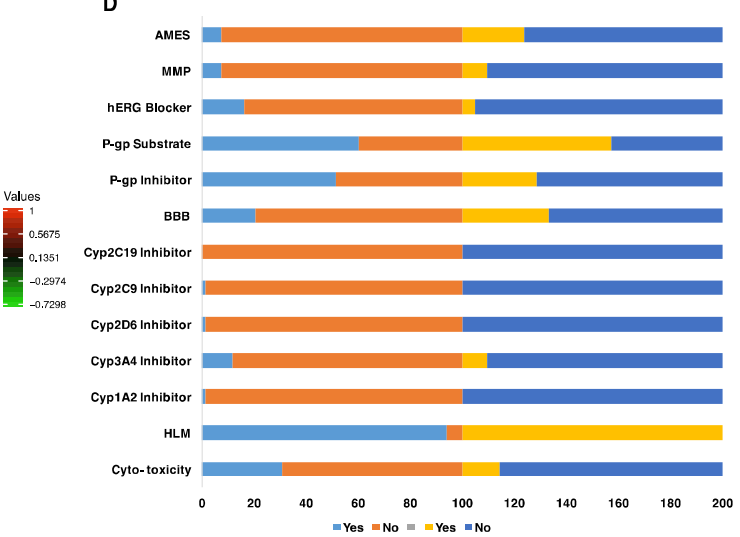


Figure 2. A) Bar graph showing the percentage of phytochemicals with top docking score from Indian medicinal plants. The horizontal axis represents the percentage of phytochemicals. The vertical axis is the names of the Indian medicinal plants.

B) The correlation (Average linkage, Pearson's distance measurement) heat map generated by Heatmapperfrom the docking scores of the 21 drugs with the 10 binding pockets of SARS-COV-2. The numbers in the left vertical axis represent the SARS-COV-2 targets: 1: Protease; 2: Spike protein, 3: NSP 10; 4: NSP 12 catalytic pocket; 5: NSP 12-NSP7 interface; 6: NSP 12-NSP 8 interface; 7: NSP 16; 8: NSP 9; 9: NSP 15; 10: NSP 3. The horizontal axis represents the 21 drugs abbreviated as: Chloroquine phosphate (CP); Chloroquine (CL); Arbidol (AR); Remdesivir (REM); Favipiravir (FAV); Lopinavir (LOP); Ritonavir (RIT); Ribavirin (RIB); Oseltamivir (OSE); Zanamivir (ZAN); Peramivir (PER); Ganciclovir (GAN); Methylprednisolone (MEP); Dexamethasone (DEX); Baricitinib (BAR); Hydroxychloroquine (HCL); Sofosbuvir (SOF); Interferon alfa-2b (INA); Camostat mesylate (CAM); Darunavir (DAR); Galidesivir / BCX-4430 (GAL). The colors represent the z-scores of the docking scores.

C) Pairwise cross correlation map (Elucidian distance measurement) of 8 ADME profiles of the 21 drugs abbreviated as F1...Fn and the phytochemicals abbreviated as P1...Pn. The orange box represents the region in the plot showing correlation between the drugs and the phytochemicals with ADME profiles which shows very low violations of the standard rules.

D) Comparative bar graph showing 13 toxicity profiles of the 21 drugs (Left panel) and the phytochemicals (right panel). Yes: the percentage of compounds showing toxicity and No: the percentage of compounds not showing toxicity. Horizontal axis represents the percentage of compounds and vertical axis is the various toxicity profiles which were obtained from vNN ADMET server.

Further, in this study 21 compounds, highly cited in literature to berepurposed for COVID 19 treatment, were also docked with 100 LGA runs against the 8 targets of SARSCOV-2 (Fig. 2B, Table S3A-S3B). Among the 21 compounds, hydroxychloroquine and Remdesivir were the most cited to be effective against SARS-CoV-2. The ADME/T profiles of these drugs have been presented in Table S4A-S4B.Interestingly it was observed that most of the 21 drugs bound to multiple targets of SARS-CoV-2 with docking score in the range: $11 \mathrm{kcal} / \mathrm{mol}$ to $-5 \mathrm{kcal} / \mathrm{mol}$. Additionally, two major clusters were observed in the heat map built with average linkage clustering and Pearson distance measurement methods using Heatmapper server (Fig. 2B). It can be observed from Fig. 2B that drugs targeting multiple targets with similar docking score were clustered together by the clustering algorithm. Among the 21 drugs, Baricitinib, Methylprednisolone, Arbidol, Dexamethasone, Hydroxycloroquine, Chlorquine and chloroquine phosphate bound to the 8 targets with binding energy $<-5 \mathrm{kcal} / \mathrm{mol}$. The most potent inhibitors were found to be Baricitinib (-7.62 $\mathrm{kcal} / \mathrm{mol})$ for spike, Methylprednisolone and Baricitinib $(\sim-8.5 \mathrm{kcal} / \mathrm{mol})$ for the main protease (NSP 5), Methylprednisolone (-9.22 kcal/mol) for NSP 10 and NSP 12 (catalytic site) $(-6.54 \mathrm{kcal} / \mathrm{mol})$, Hydroxychloroquine $(-7.73 \mathrm{kcal} / \mathrm{mol})$ and Lopinavir $(-8.33 \mathrm{kcal} / \mathrm{mol})$ for NSP 12 -NSP7 and NSP 8 interface, Chloroquine $(-10.11 \mathrm{kcal} / \mathrm{mol})$ for NSP 16 , Camostat mesylate $(-5.98 \mathrm{kcal} / \mathrm{mol})$ for NSP 9, Dexamethasone $(-7.08 \mathrm{kcal} / \mathrm{mol})$ for NSP 15 and for NSP 3 it was Baricitinib (-10.38 kcal/mol).Further, virtual screening also showed that 
NSP 16 and NSP 3 can be good drug targets for SARS CoV-2- most of the 21 drugs docked to them with low binding energy (Fig. 2B).

Further,clustering of the binding sitescan be attributed to the docking scoresof the drugs (Fig. 2B). The sites which docked multiple drugs with similar docking scores were clustered together. This led us to analyzethe similarity among the binding pocket residues of the targets that clustered together. For example, NSP 16 and NSP 3, NSP 12-NSP 8 interface and the main protease were separately clustered in two groups- the former bound to the same drugs with similar docking scores which were better thanthe latter. NSP 15 and Spike protein binding to these drugs with lesser negative docking scores were also clustered together.NSP12 D1 (catalytic site) and NSP 9 showed the worst docking scores with these 21 drugs and thus were orphans closer to the NSP 15 and Spike protein group in the clustering heat map. Whereas NSP 12-NSP7 interface and NSP 3 showing better binding with these drugs fell in between the NSP 16 and NSP 3, NSP 12-NSP 8 interface and the main protease groups (Fig. 2B, S Table S3B). It can also be comprehended from the binding site analysis that binding pockets which are more hydrophobic bound to multiple drugs with better binding scores and were thus clustered together.Very similar observations were made when the 100 top hits (66 unique) phytochemicals from virtual screening were re-docked to the 10 binding sites from 8 SARS-CoV-2 targets.

Further, the re-docking results after 100 LGA runs of the virtually screened phytochemicals have been presented in Table S4along with their ADME/T properties(Table S6). The compounds which can be good leads in terms of medicinal chemistry- showing 0 Lipinski, Veber and Egan rules violations, high Gastro Intestinal (GI) absorption, 0 PAINS (pan assay interference compounds) alert and 1-2 Brenk (to bear poor pharmacokinetics properties $)$ and very low number of lead likeness violations $(250<=$ molecular weight $<=350$, XLOGP $<=3.5$, rotable bonds $<=7$ ) have been presented in Table 2.

Table 2: Good drug leads in terms of medicinal chemistry obtained after re-docking of phytochemicals from Indian medicinal plants

\begin{tabular}{|l|l|l|l|}
\hline Phytochemical & $\begin{array}{l}\text { Docking Score } \\
\text { (Kcal/Mol) }\end{array}$ & \multicolumn{1}{c|}{$\begin{array}{c}\text { MRTD Dose } \\
\text { (md/day) }\end{array}$} & \multicolumn{1}{c|}{ Source } \\
\hline \multicolumn{3}{|c|}{ Main Protease (PDB; 6lu7) } \\
\hline 27-Deoxy-14-hydroxywithaferin A & -10.8 & 8.7 & Withaniasomnifera \\
\hline Nimolicinol & -10.09 & 84 & Azadirachtaindica \\
\hline 17-Hydroxywithaferin & -10.08 & 342 & Withaniasomnifera \\
\hline WithanolideR & -9.63 & 46 & Withaniasomnifera \\
\hline \multicolumn{5}{|c|}{ Spike (PDB 6LZG) } & Withaniasomnifera \\
\hline 27-Hydroxywithanone & -8.47 & 49 &
\end{tabular}




\begin{tabular}{|c|c|c|c|}
\hline Deoxywithastramonolide & -8.27 & 54 & Withaniasomnifera \\
\hline 27-Deoxywithaferin A & -7.82 & 303 & Withaniasomnifera \\
\hline 2,3-Dihydrowithaferin A & -7.45 & 319 & Withaniasomnifera \\
\hline \multicolumn{4}{|c|}{ NSP 10 (PDB 6w4h) } \\
\hline 27-Hydroxywithanolide B & -8.32 & 54 & Withaniasomnifera \\
\hline Anaferine & -6.22 & 196 & Withaniasomnifera \\
\hline \multicolumn{4}{|c|}{ NSP12 D1 (RNA Binding Site) (PDB 6M71) } \\
\hline 12-Deoxywithastramonolide & -7.58 & 54 & Withaniasomnifera \\
\hline \multicolumn{4}{|c|}{\begin{tabular}{|l|l} 
NSP12 D2 (NSP12-NSP7 Interface) (PDB 6M71) \\
\end{tabular}} \\
\hline Withastramonolide & -9.72 & 60 & Withaniasomnifera \\
\hline Withanolide B & -9.2 & 51 & Withaniasomnifera \\
\hline 12-Deoxywithastramonolide & -9.05 & 54 & Withaniasomnifera \\
\hline Withanolide R & -8.94 & 46 & Withaniasomnifera \\
\hline Withaferin A & -7.9 & 342 & Withaniasomnifera \\
\hline \multicolumn{4}{|c|}{ NSP12 D3 (NSP-NSP8 Interface) (PDB 6M71) } \\
\hline Withaferin A & -9.94 & 342 & Withaniasomnifera \\
\hline \multicolumn{4}{|c|}{ NSP16(PDB 6w4h) } \\
\hline Solvanol & -10.98 & 473 & Solanum nigrum \\
\hline (-)-Anaferine & -10.91 & 196 & Withaniasomnifera \\
\hline Limonin & -10.73 & 172 & Nigella sativa \\
\hline \multicolumn{4}{|c|}{ NSP9 (PDB 6w4b) } \\
\hline 27-Hydroxywithanolide B & -8.28 & 54 & Withaniasomnifera \\
\hline 12-Deoxywithastramonolide & -8.19 & 54 & Withaniasomnifera \\
\hline Azadiradionolide & -7.3 & 220 & Azadirachtaindica \\
\hline \multicolumn{4}{|c|}{ NSP15 (PDB 6w01) } \\
\hline Somniferine & -7.21 & 45 & Withaniasomnifera \\
\hline Vindolinine & -6.87 & 102 & Catharanthus roseus \\
\hline \multicolumn{4}{|c|}{ NSP3 (PDB 6w02) } \\
\hline 2,3-Dehydrosomnifericin & -12.3 & 127 & Withaniasomnifera \\
\hline WithanolideB & -11.44 & 51 & Withaniasomnifera \\
\hline 24,25-dihydrowithanolide D & -10.24 & 54 & Withaniasomnifera \\
\hline 27-Deoxy-14-hydroxywithaferin A & -9.49 & 8.7 & Withaniasomnifera \\
\hline
\end{tabular}

Other than these phytochemicals reported in Table 2, many phytochemicals with good docking scores could not satisfy the standard rules of drug likeness. It can be noted from Table S4 that Serpentinine, though violates drug-likeness rules, is the most potent phytochemical among the 1916 compound with the lowest docking score against the SARS COV-2 main protease (-13 kcal/mol). Serpentinine also docked with NSP $16(-12 \mathrm{kcal} / \mathrm{mol})$. Similarly, Terchebulin docked against three binding sites of NSP $12(\sim-11 \mathrm{kcal} / \mathrm{mol}), 7-$ Deacetyl-7-benzoylepoxyazadiradione with NSP 9 (-8.74 kcal/mol), Ashwagandhanolide docked with NSP 15 (-10.17 kcal/mol) and 2,3-Dehydrosomnifericin docked with NSP 3 ($12.3 \mathrm{kcal} / \mathrm{mol}$ ). The justification for these drugs to be tested experimentallycomes the observation of the cross correlation matrix constructed on the ADME properties of Lipinski, 
Ghose, Veber, Egan, Muegge, Lead likeness rule violations, PAINS and Brenk alerts for the 66 phytochemicals along with the 21 drugs (Fig. 2C). It was observed that the ADME profiles of most of the phytochemicals have positive correlation with the 21 drugs. Further, it can be observed from the bar graph in Fig. 2D that the phytochemicals show very less toxicity which is again comparable to the 21 drugs. Another justification comes from the reports where drug-likeness rules have been shown to be biased measurement for natural compounds as they were derived using small molecules (Loureiro et al., 2019). It was also reported that it is still a challenge to find alternative drug-likeness rules for natural compounds (Katiyar et al. 2012). Further, there are many examples of successful natural drugs which also do not obey the usual drug-likeness rules (Loureiro et al., 2019). For example, the drug paclitaxel (chemotherapy medication) does not comply with Lipinski rule of five. Conclusively it can be said that these compounds need to be studied further in vitro to confirm their experimental drug likeness.

An interesting observationmade from virtual screening results, was that the phytochemicals like the 21 repurposed drugs were able to bind to multiple targets with good docking scores. From Table S4 it can be observed that Terchebulin (Terminalia chebula) docked to 7 binding sites except NSP 16. Similar multi-potency was also observed for compounds like Serpentinine (Rauvolfia serpentine), Nimocin (Azadirachtaindica) and Ashwagandhanolide (Withaniasomnifera). It can be mentioned here that natural products are known to bind to multiple targets (Efferthet al., 2011). Moreover, according to previous research, it has been reported that binding to more than one target at the same time can lead to therapeutic efficiency decreasing probability of resistance to one target (Kadiogluet al., 2020).

A novel observation that can be reported in this paper isbased on the predicted MRTD dose (maximum recommended therapeutic dose) for the phytochemicals and the 21 drugscalculated employing the vNN server (Table 2, Supplementary Table 3B and Supplementary Table 6). It is worth mentioning that most of the phytochemicals have low MRTD dose (maximum: $691 \mathrm{mg} /$ day for a $60 \mathrm{Kg}$ body weigh individual) as compared to the repurposed drugs (maximum: $10779 \mathrm{mg} /$ day for a $60 \mathrm{Kg}$ body weigh individual). Thus it can be said that these phytochemicals possess high pseudo-potency. These predicted MRTD dose can be instrumental to estimate the starting dose in phase I clinical trials, reducing the number of animals used in preliminary toxicology studies (Schymanet al., 2017). It was also reported that low MRTD drugs often have high pseudo-potency (Liu et al., 2016). On the other hand, 
drugs of low pseudo-potency need high dose to reach the desired therapeutic effects (Liu et al., 2016).

\section{Analysis of the intermolecular interactions of the docked phytochemicals and the repurposed drugswith the drug targets of SARS-CoV-2}

The binding interactions of the lead like phytochemicals in comparison to the 21 drugs have been illustrated in Figure 3. It can be observed that residues which were reported to be structurally and functionally important in the 8 SARS-COV-2 binding sites were visualized to interact with the phytochemicals through various van der Waal's interactions (hydrogen bonds, hydrophobic contacts, aromatic ring $\pi-\pi$ interactions, etc.). It can also be observed that interacting residues in these binding sites were similar for the repurposed drugs and the phytochemicals.For example, in the case of the main protease (3CLpro) of SARSCoV-2, phytochemical moieties formed strong hydrogen bonds with the catalytic dyad residues (Cys-145 and His-41) as well as significant interactions were formed with the receptor-binding residues Gly143, His163, Met165, Glu166, Pro168 and Gln189.

It is known that the spike glycoprotein aids in virus entry by priming to angiotensinconverting enzyme 2 (ACE-2) as a receptor (McKee et al., 2020). Residues reported to be instrumental in viral entry by interacting with the ACE2 receptor were reported from the crystal structure (6lzg) are S494, N501, Q493, L455 (Shang et al. 2020). These residues were observed to interact with the phytochemicals and the repurposed drugs. It was interesting to observe that the span of residue coverage by the phytochemicals were greater than the repurposed drugs(Figure 3). It was also reported that L453 and N501 were responsible for stabilizing virus binding "hotspots" in the ACE2 receptors (Shang et al. 2020). These residues were observed to form strong hydrogen bonds $<3 \AA$ in length with the phytochemicals and the repurposed drugs.

Further, the phytochemicals and the repurposed drugs were able to form strong hydrogen bonds with the residues at the interface of NSP10-NSP16, NSP12-NSP7 and NSP12-NSP 8. Therefore, disruption of interaction among these proteins can inhibit the viral replication machinery. Further, NSP 10 in SARS-CoV with two zinc fingers is known to stimulate methyl transferase activity of NSP 16 (Bouvet et al. 2014). Thus similar role is expected in SARS-CoV-2. Residues involved in zinc coordination (C4327, C4330, C4343, H4336) identified in the crystal structure $(6 \mathrm{w} 4 \mathrm{~h})$ were observed to interact with the docked molecules. Thus binding of inhibitors at this region can inhibit its interaction with NSP 16.Nsp12 is an RNA-dependent RNA polymerase (RdRp) involved in viral replication. Nsp8 
synthesizesthe primer required for Nsp12-RdRp RNA synthesis. Further, the Nsp7 and Nsp8 enhances thedocking of Nsp12 (Wu et al. 2020). Phytochemicals and the repurposed drugs docked poorly with the catalytic pocket with Val555 as the catalytic residue. However, theywere observed to interact with these interface residues and thus can interrupt RNA synthesis by RdRp by inhibiting NSP7 and NSP 8 docking with NSP 12. NSP 3 is the ATP ribose phosphatase of SARS-CoV-2 is required for virus replication. Binding of phytochemicals and repurposed drugs were observed to form hydrogen bonds and hydrophobic interactions with the Adenosine-5-Diphosphoribose binding site in the crystal structure (6wo2). NSP 9 is most likely involved in viral replication as in SARS CoV (Friemanet al., 2012). Residues important for its dimerization can be targeted for drug development as this effects viral proliferation in SARS-CoV (Friemanet al., 2012). Phytochemicals were observed to interact with this interface residue with strong non-covalent bonds. NSP15 is an uridylate specific endoribonuclease. His235, His250, Lys290, Thr341, Tyr343, and Ser294 were reported as the catalytic residues (highly conserved) in its active site pocket (Kim et al. 2020). The phytochemicals were observed to interact with these residues better than the repurposed drugs. Thus it can be comprehended that these phytochemicals along with repurposed drugs (in conjugation or alone) can aid in COVID 19 treatment by blocking the association of these key non-structural proteins required for replication of the SARS-CoV-2 virus.

Further, evolutionary conservation scores were also calculated for these residues forming favorable interactions with the phytochemicals- through the Consurf server(Figure 3). This was performed to analyze whether these interacting residues are functionally important to the virus and if they are prone to mutations. It is well known according to the neutral theory of molecular evolution that functionally important residues vary less than less important ones (Saldanoet al., 2016).It is also known now that SARS-CoV-2 is fast evolving due to its high rate of mutations (Pachettiet al., 2020). The concern was that if the phytochemicals were interacting more with non-conserved residues than occurrence of mutation of these residues in different strains of the viruscan nullify their drugability effectrendering them non-functional in different mutated strains of the virus. Interestingly it was observed that most of the strong interactions were formed between highly conserved residues and the phytochemicals (Figure 3). These high affinity interactions with the conserved residues were more profound with the phytochemicals than the 21 repurposed drugs. Thus it can be predicted that the phytochemicals can be developed into better drug candidates can inhibit SARS-CoV-2 as positive results were obtained. A concoction of these phytochemicals 
can target the different SARS-CoV-2 proteins. This natural concoction can thus act as prophylaxis for treating SARS-CoV-2 infections along with the repurposed drugs. 


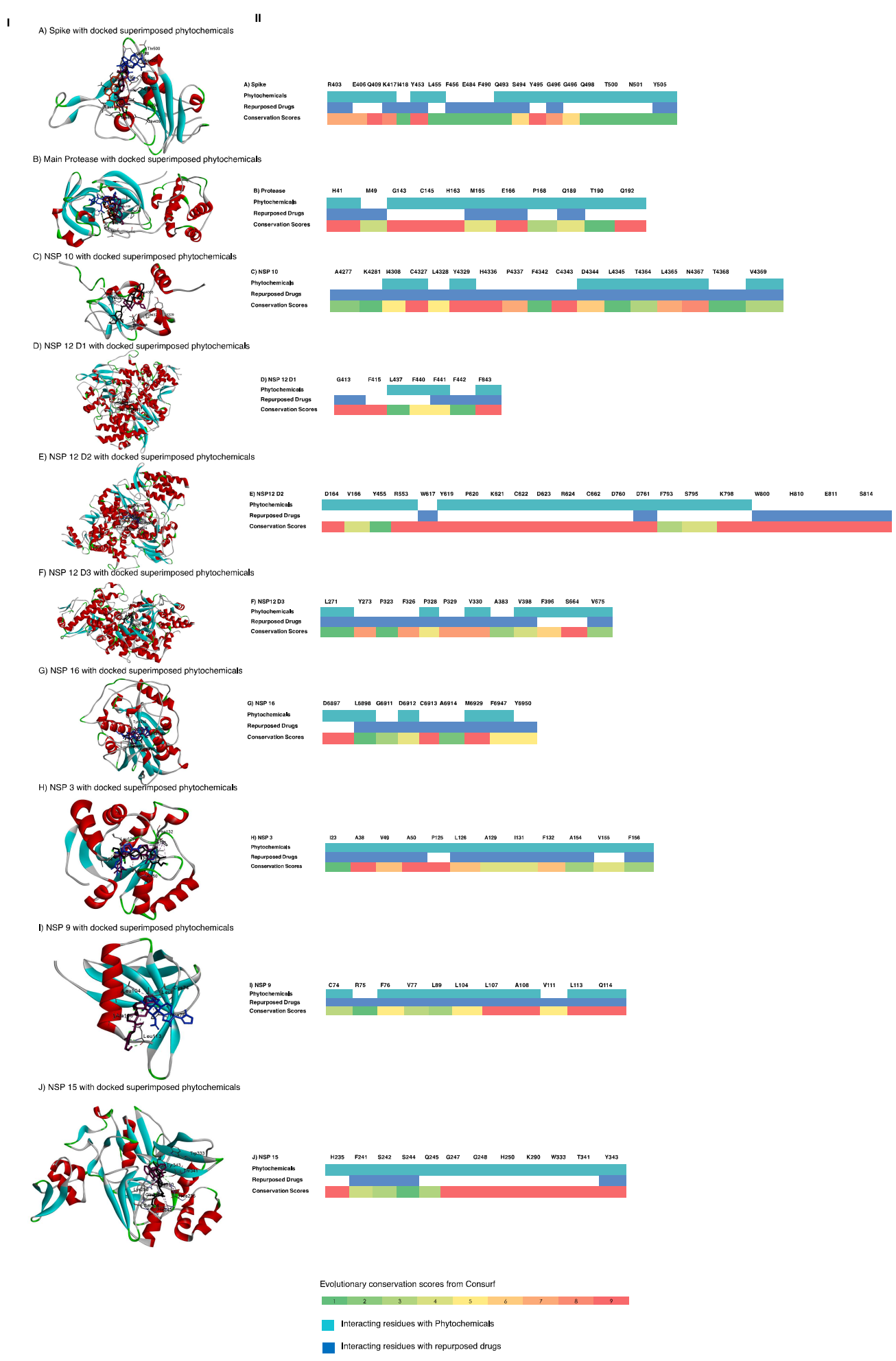

Figure 3. Interaction of amino acid residues in the binding pocket of 8 SARS-COV-2 targets (10 binding pockets). I) Cartoon representation of the 10 binding sites with the re-docked and superimposed phytochemicals(top scoring with best drug likeness properties).Reference Table 2 for the docked phytochemicals. II) Color map of the residues in the targets interacting with the top 
scoring phytochemicals and the top scoring repurposed drugs. The evolutionary conservation scores calculated by the ConSurf server have also been illustrated: 1: Low conservation to 9: high conservation (Ashkenazy et al., 2016).

\section{Conclusions}

This is the first systematic work of exploring 1916 phytochemicals from 55 Indian medicinal plants having anti-viral properties by in silico rational screening approaches to develop prophylactic treatment against SARS-Cov-2. 21 repurposed drugs were also subjected to molecular docking and compared to the phytochemicals. Top scoring phytochemicals screened were steroidal lactones from Withaniasomnifera (37\%) and triterpenoids from Azadirachtaindica (19\%) with docking score ranging from $-13 \mathrm{kcal} / \mathrm{mol}$ upto $-6 \mathrm{kcal} / \mathrm{mol}$. Comparison of ADME/T profiles of the screened phytochemicals with the repurposed drugs showed positive correlation. Further, high affinity interactions of the binding site residues of these targets were dominated by hydrogen bonds and hydrophobic interactions. Strong inter-molecular interactions were also observed to be profound with the evolutionary conserved residues- with the phytochemicals than the 21 repurposed drugs. Thus, it can be said that the phytochemicals will be effective against different mutated strains of the virus. We have also predicted the MRTD dose of these screened phytochemicals along with the repurposed drugs that can be used as a safe dose for the phase I clinical trials. It is worth mentioning that most of the phytochemicals have low MRTD dose and thus can be developed into good drug leads. Conclusively it can be proposed here that a concoction of these phytochemicals can target the different SARS-CoV-2 proteins at the same time and this natural concoction can act as prophylactic medication for treating SARS-CoV-2 infections. It is also proposed here that these phytochemicals being natural in origin can lead to develop immunity which is the first line of defense against such deadly virus. Further, this natural concoction can aid in treatment if given in conjugation with other drug therapy or used as an immunopotentiating agent with the future developed vaccines against SARS-CoV-2.

\section{Acknowledgements}

We would like to acknowledge Noor Enzymes Private Limited for providing the infrastructure and computational facilities for successfully completing this work.

\section{Disclosure statement}

No potential conflict of interest was reported by the authors.

\section{Author contributions statement}

All authors conceived, conducted and analyzed the results of experiments equally. 
Supplemental online material

Supplemental data for this article is available online

\section{References}

Ahmad, A., Javed, M. R., Rao, A. Q., \&Husnain, T. (2016). Designing and screening of universal drug from neem (Azadirachtaindica) and standard drug chemicals against influenza virus nucleoprotein. BMC Complementary and Alternative Medicine, 16(1), 519. https://doi.org/10.1186/s12906-016-1469-2

Ashkenazy, H., Abadi, S., Martz, E., Chay, O., Mayrose, I., Pupko, T., \& Ben-Tal, N. (2016). ConSurf 2016: an improved methodology to estimate and visualize evolutionary conservation in macromolecules. Nucleic Acids Research,44(W1), W344-W350. https://doi.org/10.1093/nar/gkw408

Babicki, S., Arndt, D., Marcu, A., Liang, Y., Grant, J. R., Maciejewski, A., \& Wishart, D. S. (2016). Heatmapper: web-enabled heat mapping for all. Nucleic Acids Research, 44, W147-W153. https://doi.org/10.1093/nar/gkw419

Badam, L., Joshi, S. P., \&Bedekar, S. S. (1999). 'In vitro' antiviral activity of neem (Azadirachtaindica. A. Juss) leaf extract against group B coxsackieviruses. The Journal of Communicable Diseases, 31(2), 79-90.

Baell, J. B., \& Holloway, G. A. (2010). New substructure filters for removal of pan assay interference compounds (PAINS) from screening libraries and for their exclusion in bioassays. Journal of Medicinal Chemistry, 53(7), 2719-2740. https://doi.org/10.1021/jm901137j

Bharitkar, Y. P., Bathini, S., Ojha, D., Ghosh, S., Mukherjee, H., Kuotsu, K., Kuotsu, K., Chattopadhyay, D., \& Mondal, N. B. (2014). Antibacterial and antiviral evaluation of sulfonoquinovosyldiacylglyceride: a glycolipid isolated from Azadirachtaindica leaves. Letters in Applied Microbiology, 58(2), 184-189. https://doi.org/10.1111/lam.12174

Bouvet, M., Lugari, A., Posthuma, C. C., Zevenhoven, J. C., Bernard, S., Betzi, S., Imbert, I., Canard, B., Guillemot, J. C., Lécine, P., \&Pfefferle, S. (2014). Coronavirus Nsp10, a critical co-factor for activation of multiple replicative enzymes. Journal of Biological Chemistry, 289(37), 25783-25796. https://doi.org/10.1074/jbc.M114.577353

Brenk, R., Schipani, A., James, D., Krasowski, A., Gilbert, I. H., Frearson, J., \& Wyatt, P. G. (2008). Lessons learnt from assembling screening libraries for drug discovery for neglected diseases. ChemMedChem: Chemistry Enabling Drug Discovery, 3(3), 435444. https://doi.org/10.1002/cmdc.200700139

Cai, Z., Zhang, G., Tang, B., Liu, Y., Fu, X., \& Zhang, X. (2015). Promising antiinfluenza properties of active constituent of Withaniasomnifera ayurvedic herb in targeting neuraminidase of H1N1 influenza: computational study. Cell Biochemistry and Biophysics, 72(3), 727-739. https://doi.org/10.1007/s12013-015-0524-9

Cinatl, J., Morgenstern, B., Bauer, G., Chandra, P., Rabenau, H., \&Doerr, H. W. (2003). Treatment of SARS with human interferons. The Lancet, 362(9380), 293-294. https://doi.org/10.1016/S0140-6736(03)13973-6

Contrera, J. F., Matthews, E. J., Kruhlak, N. L., \& Benz, R. D. (2004). Estimating the safe starting dose in phase I clinical trials and no observed effect level based on QSAR modeling of the human maximum recommended daily dose. Regulatory Toxicology and Pharmacology, 40(3), 185-206. https://doi.org/10.1016/j.yrtph.2004.08.004

Daina, A., \&Zoete, V. (2016). A BOILED-Egg to predict gastrointestinal absorption and brain penetration of small molecules. ChemMedChem, 11(11), 1117-1121. https://doi.org/10.1002/cmdc.201600182 
Daina, A., Michielin, O., \&Zoete, V. (2014). iLOGP: a simple, robust, and efficient description of n-octanol/water partition coefficient for drug design using the GB/SA approach. Journal of Chemical Information and Modeling, 54(12), 3284-3301. https://doi.org/10.1021/ci500467k

Daina, A., Michielin, O., \&Zoete, V. (2017). SwissADME: a free web tool to evaluate pharmacokinetics, drug-likeness and medicinal chemistry friendliness of small molecules. Scientific Reports, 7, 42717. https://doi.org/10.1038/srep42717

Dashtipour, K., Chung, J. S., Wu, A. D., \& Lew, M. F. (2007). Amantadine and Anticholinergics. In: Pahwa,RLyons,K.E.. (eds), Handbook of Parkinson's Disease, 293-308.

Dassault SystèmesBIOVIA,. (2020). BIOVIA Discovery Studio Visualiser, v20.1..0.19295, San Diego, CA, USA.

Duffy, S. (2018). Why are RNA virus mutation rates so damn high? PLoS Biology, 16(8), e3000003. https://doi.org/10.1371/journal.pbio.3000003

Efferth, T., \& Koch, E. (2011). Complex interactions between phytochemicals. The multi- $\quad$ target therapeutic concept of phytotherapy. Current Drug Targets, 12(1), $122-$ 132. https://doi.org/10.2174/138945011793591626

Forli, S., Huey, R., Pique, M. E., Sanner, M. F., Goodsell, D. S., \& Olson, A. J. (2016). Computational protein-ligand docking and virtual drug screening with the AutoDock suite. Nature Protocols, 11(5), 905-919. https://doi.org/10.1038/nprot.2016.051

Frieman, M., Yount, B., Agnihothram, S., Page, C., Donaldson, E., Roberts, A., Vogel, L., Woodruff, B., Scorpio, D., Subbarao, K., \& Baric, R. S. (2012). Molecular determinants of severe acute respiratory syndrome coronavirus pathogenesis and virulence in young and aged mouse models of human disease. Journal of Virology, 86(2), 884-897. https://doi.org/10.1128/JVI.05957-11

Ganjhu, R. K., Mudgal, P. P., Maity, H., Dowarha, D., Devadiga, S., Nag, S., \&Arunkumar, G. (2015). Herbal plants and plant preparations as remedial approach for viral diseases. VirusDisease, 26(4), 225-236. https://doi.org/10.1007/s13337-015$\underline{0276-6}$

Gao, Y., Yan, L., Huang, Y., Liu, F., Zhao, Y., Cao, L., Wang, T., Sun, Q., Ming, Z., Zhang, L., Ge, J., Zheng, L., Zhang, Y., Wang, H., Zhu, Y., Zhu, C., Hu, T., Hua, T., Zhang, B., Yang, X., Li, J., Yang, H., Liu, Z., Xu, W., Guddat, L. W., Wang, Q., Lou, Z., \& Rao, Z,. (2020). Structure of RNA-dependent RNA polymerase from 2019$\mathrm{nCoV}$, a major antiviral drug target. BioRxiv. https://doi.org/10.1101/2020.03.16.993386

Gautret, P., Lagier, J. C., Parola, P., Meddeb, L., Mailhe, M., Doudier, B., Courjon, J., Giordanengo, V., Vieira, V. E., Dupont, H. T., \&Honoré, S. (2020). Hydroxychloroquine and azithromycin as a treatment of COVID-19: results of an open-label non-randomized clinical trial. International Journal of Antimicrobial Agents, 105949. https://doi.org/10.1016/j.ijantimicag.2020.105949

Grover, A., Agrawal, V., Shandilya, A., Bisaria, V. S., \& Sundar, D. (2011). Nonnucleosidic inhibition of Herpes simplex virus DNA polymerase: mechanistic insights into the anti-herpetic mode of action of herbal drug withaferin A. BMC Bioinformatics. 12, S22. https://doi.org/10.1186/1471-2105-12-S13-S22

Harvey, A. L. (2008). Natural products in drug discovery. Drug Discovery Today, 13(1920), 894-901. https://doi.org/10.1016/j.drudis.2008.07.004

Huang, J., Song, W., Huang, H., \& Sun, Q. (2020). Pharmacological Therapeutics Targeting RNA-Dependent RNA Polymerase, Proteinase and Spike Protein: From Mechanistic Studies to Clinical Trials for COVID-19. Journal of Clinical Medicine, 9(4), 1131. https://doi.org/10.3390/jcm9041131 
Jadhav, P., Kapoor, N., Thomas, B., Lal, H., \&Kshirsagar, N. (2012). Antiviral potential of selected Indian medicinal (ayurvedic) plants against herpes simplex virus 1 and 2. North American Journal of Medical Sciences, 4(12), 641-647. https://doi.org/10.4103/1947-2714.104316

Jain, J., Narayanan, V., Chaturvedi, S., Pai, S., \& Sunil, S. (2018). In vivo evaluation of Withaniasomnifera-based Indian traditional formulation (AmukkaraChoornam), against chikungunya virus-induced morbidity and arthralgia. Journal of EvidenceBased Integrative Medicine, 23, 1-7. https://doi.org/10.1177/2156587218757661

Jassim, S. A. A., \&Naji, M. A. (2003). Novel antiviral agents: a medicinal plant perspective. Journal of Applied Microbiology,95(3), 412-427. https://doi.org/10.1046/j.1365-2672.2003.02026.x

Kadioglu, O., Saeed, M., Johannes Greten, H., \&Efferth, T. (2020). Identification of novel compounds against three targets of SARS CoV-2 coronavirus by combined virtual screening and supervised machine learning. [Preprint]. Bulletin of the World Health Organization. https://doi.org/10.2471/BLT.20.255943

Katiyar, C., Gupta, A., Kanjilal, S., \&Katiyar, S. (2012). Drug discovery from plant sources: An integrated approach. Ayu,33(1), 10-19. https://doi.org/10.4103/0974$\underline{8520.100295}$

Kaul, T. N., Middleton Jr, E., \&Ogra, P. L. (1985). Antiviral effect of flavonoids on

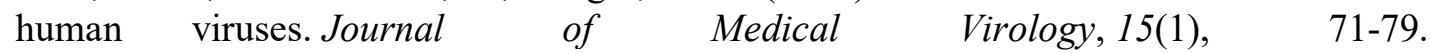
https://doi.org/10.1002/jmv.1890150110

Khan, Y. D., \&Roomi, M. S. (2020). Promising compounds for treatment of COVID19. VAWKUM Transactions on Computer Sciences, 17(1), 1-8.

Kim, Y., Jedrzejczak, R., Maltseva, N. I., Wilamowski, M., Endres, M., Godzik, A., Michalska, K., \&Joachimiak, A. (2020). Crystal structure of Nsp15 endoribonuclease NendoU from SARS-CoV-2. Protein Science. https://doi.org/10.1002/pro.3873

Kutluay, S. B., Doroghazi, J., Roemer, M. E., \&Triezenberg, S. J. (2008). Curcumin inhibits herpes simplex virus immediate-early gene expression by a mechanism independent of p300/CBP histone acetyltransferase activity. Virology, 373(2), 23924. $\quad$ https://doi.org/10.1016/j.virol.2007.11.028

Li, Y., Liu, X., Guo, L., Li, J., Zhong, D., Zhang, Y., Clarke, M., \&Jin, R. (2020). Traditional Chinese herbal medicine for treating novel coronavirus (COVID-19) pneumonia: protocol for a systematic review and meta-analysis. Systematic Reviews, 9, 75. https://doi.org/10.1186/s13643-020-01343-4

Lin, L. T., Chen, T. Y., Lin, S. C., Chung, C. Y., Lin, T. C., Wang, G. H., Anderson, R., Lin, C. C., \& Richardson, C. D. (2013). Broad-spectrum antiviral activity of chebulagic acid and punicalagin against viruses that use glycosaminoglycans for entry. BMC Microbiology, 13, 187. https://doi.org/10.1186/1471-2180-13-187

Lin, L. T., Hsu, W. C., \& Lin, C. C. (2014). Antiviral natural products and herbal medicines. Journal of Traditional and Complementary Medicine, 4(1), 24-35. https://doi.org/10.4103/2225-4110.124335

Lipinski, C. A., Lombardo, F., Dominy, B. W., \& Feeney, P. J. (1997). Experimental and computational approaches to estimate solubility and permeability in drug discovery and development settings. Advanced Drug Delivery Reviews, 23(1-3), 3-25. https://doi.org/10.1016/S0169-409X(96)00423-1

Liu, T., Oprea, T., Ursu, O., Hasselgren, C., \& Altman, R. B. (2016). Estimation of maximum recommended therapeutic dose using predicted promiscuity and potency. Clinical and Translational Science, 9(6), 311-320. https://doi.org/10.1111/cts.12422 
Loureiro, D. R., Soares, J. X., Costa, J. C., Magalhães, Á. F., Azevedo, C. M., Pinto, M. M., \& Afonso, C. M. (2019). Structures, activities and drug-likeness of antiinfective xanthone derivatives isolated from the marine environment: a review. Molecules, 24(2), 243. https://doi.org/10.3390/molecules24020243

McKee, D. L., Sternberg, A., Stange, U., Laufer, S., \&Naujokat, C. (2020). Candidate drugs against SARS-CoV-2 and COVID-19. Pharmacological Research, 157, 104859. https://doi.org/10.1016/j.phrs.2020.104859

Mohanraj, K., Karthikeyan, B. S., Vivek-Ananth, R. P., Chand, R. B., Aparna, S. R., Mangalapandi, P., \&Samal, A. (2018). IMPPAT: A curated database of Indian medicinal plants, phytochemistry and therapeutics. Scientific Reports, 8, 4329. https://doi.org/10.1038/s41598-018-22631-z

Morris, G. M., Huey, R., Lindstrom, W., Sanner, M. F., Belew, R. K., Goodsell, D. S., \& Olson, A. J. (2009). AutoDock4 and AutoDockTools4: Automated docking with selective receptor flexibility. Journal of Computational Chemistry, 30(16), 27852791. https://doi.org/10.1002/jcc. 21256

Moulton, B. C., \& Fryer, A. D. (2011). Muscarinic receptor antagonists, from folklore to pharmacology; finding drugs that actually work in asthma and COPD. British Journal of Pharmacology, 163(1), 44-52. https://doi.org/10.1111/j.1476-5381.2010.01190.x

Nadkarni, K. M., \& Nadkarni, A. K. (1976). Indian Materia Medica, Vol 1, 3rd ed., M/S Popular PrakasanPvt. Ltd., Mumbai, India.

Pachetti, M., Marini, B., Benedetti, F., Giudici, F., Mauro, E., Storici, P., Masciovecchio, C., Angeletti, S., Ciccozzi, M., Gallo, R. C., \& Zella, D. (2020). Emerging SARS-CoV-2 mutation hot spots include a novel RNA-dependent-RNA polymerase variant. Journal of translational medicine, 18(1), 1-9. https://doi.org/10.1186/s12967-020-02344-6

Pachetti, M., Marini, B., Benedetti, F., Giudici, F., Mauro, E., Storici, P., Masciovecchio,

C., Angeletti, S., Ciccozzi, M., Gallo, R.C. and Zella, D., 2020. Emerging SARS-CoV-2 mutation hot spots include a novel RNA-dependent-RNA polymerase variant. Journal of translational medicine, 18, 179. https://doi.org/10.1186/s12967-020-02344-6

Pathak, K., \& Zaman, K. (2013). Antiviral activity of some Indian medicinal herbs. Indian Journal of Pharmacy Practice, 6(2), 13-15.

Pathania, S., Ramakrishnan, S. M., Randhawa, V., \&Bagler, G. (2015). SerpentinaDB: a database of plant-derived molecules of Rauvolfiaserpentina. BMC Complementary and Alternative Medicine, 15, 262. https://doi.org/10.1186/s12906-015-0683-7

Pavelka, A., Chovancova, E., \&Damborsky, J. (2009). HotSpot Wizard: a web server for identification of hot spots in protein engineering. Nucleic Acids Research, 37(suppl_2), W376-W383. https://doi.org/10.1093/nar/gkp410

Peck, K. M., \&Lauring, A. S. (2018). Complexities of viral mutation rates. Journal of Virology, 92(14), e01031-17. https://doi.org/10.1128/JVI.01031-17

Polur, H., Joshi, T., Workman, C. T., Lavekar, G., \&Kouskoumvekaki, I. (2011). Back to the roots: prediction of biologically active natural products from Ayurveda traditional medicine. Molecular Informatics, 30(2-3), 181-187. https://doi.org/10.1002/minf.201000163

Rajkumar, V., Guha, G., \& Kumar, R. A. (2011). Antioxidant and anti-neoplastic activities of Picrorhizakurroa extracts. Food and Chemical Toxicology, 49(2), 363369. https://doi.org/10.1016/j.fct.2010.11.009

Reiter, R. J., Tan, D. X., Zhou, Z., Cruz, M. H. C., Fuentes-Broto, L., \&Galano, A. (2015). Phytomelatonin: assisting plants to survive and thrive. Molecules, 20(4), 73967437. https://doi.org/10.3390/molecules20047396

Sadowski, J., Gasteiger, J., \&Klebe, G. (1994). Comparison of automatic threedimensional model builders using 639 X-ray structures. Journal of Chemical 
https://doi.org/10.1021/ci00020a039

Saini, A. (2016). Physicians of ancient India. Journal of Family Medicine and Primary Care, 5(2), 254-258. https://doi.org/10.4103/2249-4863.192322

Saldaño, T. E., Monzon, A. M., Parisi, G., \& Fernandez-Alberti, S. (2016). Evolutionary conserved positions define protein conformational diversity. PLoS Computational Biology, 12(3), e1004775. https://doi.org/10.1371/journal.pcbi.1004775

Salehi, B., Kumar, N. V. A., Şener, B., Sharifi-Rad, M., Kılı̨̧, M., Mahady, G. B., Vlaisavljevic, S., Iriti, M., Kobarfard, F., Setzer, W. N., \&Ayatollahi, S. A. (2018). Medicinal plants used in the treatment of human immunodeficiency virus. International Journal of Molecular Sciences, 19(5), 1459. https://doi.org/10.3390/ijms19051459

Schyman, P., Liu, R., Desai, V., \&Wallqvist, A. (2017). vNN web server for ADMET $\begin{array}{llll}\text { predictions. Frontiers in } & \text { Pharmacology, } 8,\end{array}$ https://doi.org/10.3389/fphar.2017.00889

Shang, J., Ye, G., Shi, K., Wan, Y., Luo, C., Aihara, H., Geng, Q., Auerbach, A., \& Li, F. (2020). Structural basis of receptor recognition by SARS-CoV-2. Nature, 581, 221224. https://doi.org/10.1038/s41586-020-2179-y

Stratton, C. F., Newman, D. J., \& Tan, D. S. (2015). Cheminformatic comparison of approved drugs from natural product versus synthetic origins. Bioorganic \& Medicinal Chemistry Letters, 25(21), 4802-4807. https://doi.org/10.1016/j.bmcl.2015.07.014

Tahir ul Qamar, M., Maryam, A., Muneer, I., Xing, F., Ashfaq, U. A., Khan, F. A., Anwar, F., Geesi, M. H., Khalid, R. R., Rauf, S. A., \& Siddiqi, A. R. (2019). Computational screening of medicinal plant phytochemicals to discover potent panserotype inhibitors against dengue virus. Scientific Reports, 9, 1443. https://doi.org/10.1038/s41598-018-38450-1

Teague, S. J., Davis, A. M., Leeson, P. D., \&Oprea, T. (1999). The design of leadlike combinatorial libraries. AngewandteChemie International Edition, 38(24), 37433748. https://doi.org/10.1002/(SICI)1521-3773(19991216)38:24\%3C3743::AIDANIE3743\%3E3.0.CO;2-U

The Lancet. (2020). COVID-19: fighting panic with information. Lancet, 395(10224), 537. https://doi.org/10.1016/S0140-6736(20)30379-2

World Health Organization. (2020). Coronavirus disease 2019 (COVID-19): situation report, 35.https://www.who.int/docs/default-source/coronaviruse/situation-

reports/20200224-sitrep-35-covid-19.pdf?sfvrsn=1ac4218d 2(Published online February $24^{\text {th }}, 2020$; Date of access: May $14^{\text {th }}, 2020$ ).

Wu, C., Liu, Y., Yang, Y., Zhang, P., Zhong, W., Wang, Y., Wang, Q., Xu, Y., Li, M., Li, X., \& Zheng, M. (2020). Analysis of therapeutic targets for SARS-CoV-2 and discovery of potential drugs by computational methods. Acta PharmaceuticaSinica B. https://doi.org/10.1016/j.apsb.2020.02.008

Zhao, C., Ye, Z., Ma, Z. X., Wildman, S. A., Blaszczyk, S. A., Hu, L., Guizei, I. A., \& Tang, W. (2019). A general strategy for diversifying complex natural products to polycyclic scaffolds with medium-sized rings. Nature Communications, 10(1), 1-10. https://doi.org/10.1038/s41467-019-11976-2 